\title{
The Study of Comprehensive Risk Management and Corporate Finance Constraints
}

\author{
Qingqing LuoChen ${ }^{1,}$ *, Mengyuan $\mathrm{Chen}^{2}$, Jie Liao ${ }^{3}$ and Zhongqi $\mathrm{Xu}^{4}$ \\ ${ }^{1}$ School of Accounting and Finance, Curtin University, Perth, 6102, Western Australia \\ ${ }^{2}$ School of Tourism and Hospitality, Management Development Institute of Singapore, Singapore, 148951, Singapore \\ ${ }^{3}$ Cass Business School, London EC1Y 8TZ, United Kingdom \\ ${ }^{4}$ Faculty of Management and Economics, Dalian University of Technology, Dalian, 116024, China
}

\begin{abstract}
The reasons why companies implement comprehensive risk management and the benefits it can bring to companies have been a subject of academic interest. However, there is still room for further exploration of this topic for the following three reasons: firstly, most of the existing literature is focused on the study of corporate performance and value, and there is less research on the level of corporate financing constraints; secondly, a few papers have initially explored the relationship between the implementation of comprehensive risk management and corporate financing costs, but the research on the intrinsic impact mechanism remains at the theoretical level and lacks empirical testing Finally, comprehensive risk management has been a hot topic in recent years, but most of the literature has focused on developed countries such as Europe and the US, and domestic research is still very limited. Therefore, this paper attempts to empirically test how the implementation of comprehensive risk management affects corporate financing constraints, in the hope that it can complement the existing literature.
\end{abstract}

Keywords: Comprehensive risk management, Financing constraints, Treatment effects.

\section{Background of Enterprise Risk Management}

In 2004, the Committee of Sponsoring Organizations (COSO) issued the Enterprise Risk Management - Integrated Framework (ERMIF), which formally defines comprehensive risk management as "an integrated approach to risk management". In 2004, the Committee of Sponsoring Organisation (COSO) issued the Enterprise Risk Management - Integrated Framework, which formally defines comprehensive risk management as " It is applied in strategy formulation and throughout the enterprise by the board of directors, management and other personnel to identify potential issues that may affect the subject, manage risks to keep them within the subject's risk capacity, and provide reasonable assurance of the subject's achievement", and consists of eight major components: internal environment, purpose setting, event identification, risk The COSO Committee's definition of comprehensive risk management and the framework it has developed have quickly gained widespread recognition in the global business and academic communities. In 2006, the State-owned Assets Supervision and Administration Commission (SASAC) promulgated the "Guidelines on Comprehensive Risk Management for Central Enterprises", which for the first time explicitly required central enterprises to gradually carry out comprehensive risk management, establish a sound long-term mechanism for comprehensive risk management and promote sound corporate development. Under the impetus of the "Guidelines on Comprehensive Risk Management for Central Enterprises", more and more domestic listed enterprises have realised the importance of comprehensive risk management and started to implement it.

Much of the research on the advantages of implementing comprehensive risk management has focused on studies of firm performance, while research on how the implementation of comprehensive risk management affects firms' financing costs and financing constraints remains limited. Berry-Stölzle and $\mathrm{Xu}$ (2018) modelled the impact of firms' adoption of comprehensive risk management and comprehensive risk management on the cost of capital using data from the US insurance industry, which found that the implementation of comprehensive risk management significantly reduced firms' cost of capital; Wang et al. (2018), based on data from firms in Taiwan, China, found that weaker comprehensive risk management systems may portend poor control mechanisms and attract more investor oversight, raising the cost of external capital and damaging the long-term value of firms. Existing research mentions that implementing comprehensive risk management can reduce the cost of capital but does not empirically test the path of impact.

From a worldwide perspective, financing constraints are a common problem faced by enterprises. At present, China's economy is in a critical period of transforming its development mode, optimising its economic structure, and transforming its growth momentum after entering a new era, and the financing constraints faced by domestic enterprises may be even more serious. This paper finds that the implementation of comprehensive risk management can significantly alleviate the financing constraints of enterprises and provides theoretical and empirical support for enterprises to manage risks in an integrated manner by transforming their risk management approach.

The paper also analyses different initiatives to implement risk management and finds empirically that elevating comprehensive risk management to the strategic level is more conducive to alleviating financing constraints than simply implementing comprehensive risk management. In particular, the establishment of a chief risk officer is more effective in alleviating financing constraints than comprehensive risk management reporting and the establishment of a risk management committee. This has implications for the types of comprehensive risk management measures that companies can adopt to alleviate financing constraints. 


\section{Theoretical Development Related to Comprehensive Risk Management}

Comprehensive Risk Management (ERM) is the method and process by which a business attempts to contain the outcomes from various types of uncertainty within expected acceptable limits in order to ensure and promote the achievement of the overall interests of the organisation in achieving its future strategic objectives. The earliest and later widely accepted and borrowed definition of Total Risk Management is the integrated concept of Total Risk Management proposed by the Committee of Sponsoring Organisations (COSO) of the US National Committee on Fraudulent Financial Reporting, to which the Treadway Commission belongs, in September 2004, based on the Internal Control Framework: Total Risk Management is a process, which is implemented by a subject's board of directors, the In 2006, the State-owned Assets Supervision and Administration Commission (SASAC) issued the "Guidelines on Comprehensive Risk Management for Central Enterprises", which defines comprehensive risk management as a process whereby an enterprise, around its overall business objectives process and method of providing reasonable assurance for the achievement of the overall objectives of risk management by implementing the basic processes of risk management in all aspects of enterprise management and operation, fostering a good risk management culture, and establishing a sound comprehensive risk management system, including risk management strategies, risk management financial measures, organisational and functional systems for risk management, risk management information systems and internal control systems. The academic definition of comprehensive risk management looks more at the overall management of risk and the process of value creation than at the regulatory level (Bromiley et al., 2015), Meulbroek (2002) sees integrated risk management as the identification and assessment of collective risks affecting the value of the firm and the implementation of a company-wide strategy to manage these risks, Liebenberg and Hoyt (2003) distinguish comprehensive risk management from the traditional 'silo' approach to enterprise risk management, arguing that comprehensive risk management enables firms to benefit from an integrated risk management approach that shifts the focus of the risk management function from a primarily defensive function to one that is increasingly offensive and It also enables companies to manage a wide range of risks in an integrated and holistic manner. Despite the official definition of comprehensive risk management, it is sometimes difficult to determine whether and to what extent a company has implemented comprehensive risk management, as companies do not directly disclose their attitude towards risk management in general during the research process (Liebenberg and Hoyt, 2003).

In terms of indicator construction, in order to construct variables for the implementation of comprehensive risk management in enterprises, some scholars have used keyword searches such as "comprehensive risk management", "risk management committee" and "chief risk officer " to test the effect of a firm's implementation of comprehensive risk management before and after (Pagach and Warr, 2011) or to quantify the presence of comprehensive risk management in the form of binary variables (Hoyt and Liebenberg, 2011; Lechner and Gatzert, 2018); others use more sophisticated methods to measure the degree of implementation of comprehensive risk management, such as the use of Standard \& Poor's ERM ratings or the RIMS level of ERM maturity (Bohnert et al., 2019; Farrell and Gallagher, 2015; Callahan and Soileau, 2017); Gordon et al. (2009) constructed an ERM index to measure the complexity of implementing comprehensive risk management in a company has also become one of the methods chosen by subsequent scholars to construct ERM indicators (Malik et al., 2020).

\section{Comprehensive Risk Management and Financing Constraints}

Unlike traditional risk management approaches, comprehensive risk management, by integrating all risk categories, can use natural hedges to avoid duplication of risk management expenditures, while helping firms avoid the accumulation of unforeseen risks from different sources and reducing the likelihood that firms will have to raise external funding (Berry-Stölzle and $\mathrm{Xu}$, 2018). Implementing comprehensive risk management can also improve the disclosure of information by firms, helping them to better inform the outside world about their risk profile and serve as a signal that they are committed to improving risk management, with the disclosure of risk information leading to improved information asymmetry and agency problems (Hoyt and Liebenberg, 2011).

Implementing comprehensive risk management can also mitigate a firm's financing constraints by reducing its systemic risk. Contrary to the traditional belief that risk management cannot reduce systemic risk, Hann et al. (2013) argue that co-insurance between business units of firms can reduce systemic risk by avoiding countercyclical needless losses, finding that the average cost of capital is lower for diversified firms compared to a comparable portfolio of independent firms, and furthermore, diversified firms with lower sectoral cash flow correlation have a also have a lower cost of capital, which is consistent with the co-insurance effect. Hao-Min $\mathrm{Wu}$ et al. (2017) find that diversification facilitates the provision of business credit by increasing the firm's access to bank credit and thus ultimately alleviates the firm's financing constraints. Although the agency problem may be exacerbated by complex organisational structures, diversification can still mitigate corporate financing constraints by building internal capital markets through the co-insurance effect. In a well-designed comprehensive risk management plan, firms integrate risk management into the strategic planning process, address the overall risks in strategy, finance, and operations in a single overarching process, focus on the correlation between risks, and recognise the natural hedging relationship between risks, which is similar to a coinsurance effect that can avoid countercyclical needless losses and reduce systemic risk, thus alleviating the financing constraints of firms ( Eckles et al., 2014; Ai et al., 2018; Berry-Stölzle and $\mathrm{Xu}, 2018$ ).

\section{Summary}

Currently, most foreign research on comprehensive risk management focuses on its determinants and relevance to firm performance and value creation. Research on the impact of corporate implementation of comprehensive risk management on corporate financing constraints is still relatively scarce and studies have focused on the US insurance industry (Berry-Stölzle and Xu, 2018), with few cross-industry studies. At the same time, the existing studies 
have not conducted direct empirical analysis of the mechanisms underlying the impact of implementing comprehensive risk management on corporate financing constraints. Most domestic studies on comprehensive risk management stay at the theoretical level, and a few preliminary explorations have been conducted on the implementation of comprehensive risk management to improve the operational efficiency and increase the intrinsic value of firms, but no literature has yet investigated the impact of implementing comprehensive risk management on corporate financing constraints.

\section{References}

[1] Berry-Stölzle T. R. and Xu J., Enterprise Risk Management and the Cost of Capital, Journal of Risk and Insurance, 2018, 85(1), pp.159-201.

[2] Bromiley P., McShane M., Nair A., Rustambekov E., Enterprise Risk Management: Review, Critique, and Research Directions, Long Range Planning, 2015, 48(4), pp.265-276.

[3] Callahan C. and Soileau J., Does Enterprise Risk Management Enhance Operating Performance?, Advances in Accounting, 2017, 37, pp.122-139.

[4] Eckles D. L., Hoyt R. E., Miller S. M., The Impact of Enterprise Risk Management On the Marginal Cost of Reducing Risk: Evidence From the Insurance Industry, Journal of Banking \& Finance, 2014, 43, pp.247-261.

[5] Farrell M. and Gallagher R., The Valuation Implications of Enterprise Risk Management Maturity, Journal of Risk and Insurance, 2015, 82(3), pp.625-657.

[6] Gordon L. A., Loeb M. P., Tseng C., Enterprise Risk Management and Firm Performance: A Contingency
Perspective, Journal of Accounting and Public Policy, 2009, 28(4), pp.301-327.

[7] Hadlock C. J. and Pierce J. R., New Evidence on Measuring Financial Constraints: Moving Beyond the KZ Index, Review of Financial Studies, 2010, 23(5), pp.1909-1940.

[8] Hoyt R. E. and Liebenberg A. P., The Value of Enterprise Risk Management, The Journal of Risk and Insurance, 2011, 78(4), pp.795-822.

[9] Liebenberg A. P. and Hoyt R. E., The Determinants of Enterprise Risk Management: Evidence From the Appointment of Chief Risk Officers, Risk Management and Insurance Review, 2003, 6(1), pp.37-52.

[10] Lundqvist S. A. and Vilhelmsson A., Enterprise Risk Management and Default Risk: Evidence from the Banking Industry, Journal of Risk and Insurance, 2018, 85(1), pp.127157.

[11] Malik M. F., Zaman M., Buckby S., Enterprise Risk Management and Firm Performance: Role of the Risk Committee, Journal of Contemporary Accounting \& Economics, 2020, 16(1), pp.100178.

[12] Meulbroek L. K., A Senior Manager's Guide to Integrated Risk Management, Journal of Applied Corporate Finance, 2002, 14(4), pp.56-70.

[13] Pagach D. and Warr R., The Characteristics of Firms that Hire Chief Risk Officers, Journal of Risk and Insurance, 2011, 78(1), pp.185-211.

[14] Wang T., Lin Y., Werner E. M., Chang H., The Relationship Between External Financing Activities and Earnings Management: Evidence From Enterprise Risk Management, International Review of Economics \& Finance, 2018, 58, pp.312-329. 